\title{
INDIRECT EVIDENCES OF CONFORMATIONAL REGULATION IN PROTEIN REACTIONS: HOW MUCH CAN BE LEARNT?
}

\section{L.N. CHRISTOPHOROV}

\author{
PACS 87.15.Hp, 64.70.P-, \\ Bogolyubov Institute for Theoretical Physics, Nat. Acad. of Sci. of Ukraine \\ (14b, Metrologichna Str., Kyiv 03680, Ukraine)
}

(c) 2012

\begin{abstract}
Almost all reactions of proteins manifest deviations from the simple behaviour prescribed by standard (bio)chemical kinetics. This is caused by the extraordinary structural lability of protein macromolecules which is often not less important for the reaction efficiency than the properties of the active center. Unveiling the mechanisms of structural regulation encounters serious difficulties because of their hidden character, as either modern experiments or computational methods still fall short of monitoring simultaneously the reaction events and concomitant conformational changes, so that one has to decipher the reaction kinetics only. Nevertheless, it is possible to come to reliable conclusions on the mode of operation of proteins and the character of their structural relaxation with the help of a convenient and computationally accessible approach expounded in the present paper.
\end{abstract}

\section{Introduction}

The biochemical reactions performed by an enzyme proceed in a so-called active center - a protein globule domain, specially organized for reactions of a certain type. Usually, the active center takes only a relatively small part of the globule. The latter practically plays the role of a reaction medium.

How active is this medium? Bearing the remarkable structural lability of a protein macromolecule in mind, one can suppose that this property alone can ensure the distinctions between even simplest biochemical reactions (such as sorption/desorption of ligands or electron/proton transfer) and those within the framework of standard chemical kinetics [1]. Yet, the importance of the protein conformational changeability came to the fore not so long ago, perhaps, since the mid-1970s only. Thus, when studying the processes of protein denaturation, C. Anfinsen noticed the possibility of many postrenaturation native tertiary structures, not identical to the initial pre-denaturation ones [2]. Investigating the kinetics of carbon monoxide rebinding to myoglobin $\mathrm{Mb}$ in the biophysical system MbCO basic in our context, R.H. Austin et al. came to the conclusion that myoglobin "not just has one well-defined structure but a number of similar ones, sometimes called conformers or peers" [3]. Perhaps, the most vivid conclusion was made by G. Weber: "Indeed, the protein molecule model resulting from X-ray crystallography is a 'platonic' protein, well removed in its perfection from the kicking and screaming 'stochastic' molecule that we infer must exist in solution" [4]. Obviously, the presence of the solvent (for example, the hydration shell $\sim 5 \AA$ thick of myoglobin contains about 2000 water molecules [5]), crucial for the protein flexibility and the function, adds even more to the multiplicity of conformational substates.

Both experimental and theoretical approaches to the analysis of the role of the conformational mobility of proteins in their reactions encounter considerable (perhaps, fundamental [6]) difficulties. Even modern angstromresolved X-raying is able to display only the initial and final structures which, as valuable as they are, do not uncover the reaction kinetic mechanisms. It should be also noted that those beautiful pictures reflect average (moreover, mostly rather low-temperature) structures only since individual atoms, as is shown by Mössbauer spectroscopy, can have B-factors up to $20 \AA^{2}$ even for bestdiffracting protein crystals, and most water molecules cannot be resolved because of a large variance in their positions [7, 8]. On the other hand, IR- and optical spectroscopy provide the high-precision reaction kinetics which, however, brings only indirect information about the structure-function coupling. The same goes, in fact, for single-molecule enzymology [9]. By and large, it is hard to expect the possibility of a simultaneous experimental monitoring of the reaction kinetics and concomitant conformational changes (except, maybe, the fastest ones) because of a great disparity in corresponding time scales: micro- to milliseconds for reactions themselves and up to seconds or even much longer for slow structural rearrangements and fluctuations. Under the circumstances, the problem looks insurmountable for the best modern computer methods, too. No wonder that there exist the views about searching for some organizing prin- 
ciples for complex systems (starting from biomolecules) beyond microscopic approaches; the latter may turn out to be helpless or even misleading [6].

In what follows, I shall try to show what can be, nevertheless, extracted from those indirect evidences of contributions of the protein conformational subsystem into the protein functioning. An only biophysical system (photosynthetic reaction center, $\mathrm{RC}$ ) and an only experimental method (optical spectroscopy) will be involved, as well as an only relatively simple theoretical model. Yet, this will be sufficient for making both some important quantitative evaluations and quite general conclusions on the essence of the structure-function coupling in proteins and the mechanisms of biochemical reactions.

\section{Tools}

In our theoretical approach, we use a model that involves only two states, $\mathbf{0}$ and $\mathbf{1}$, of the reaction which is supposed to be 'simple'. Those could represent, for example, an enzyme with or without a ligand, just like in the most studied $\mathrm{Mb}+\mathrm{CO} \rightarrow \mathrm{MbCO}$ reaction $[3,5,10]$, or the states with the transferred electron on the 'donor' or 'acceptor' cofactors, just like in the another popular biophysical model, namely, the pigment-protein complex of a photosynthetic reaction center [11, 12]. As for slow conformational motions of a protein, we suppose that all their multiplicity can be reduced to a single generalized continuous structural coordinate $x$. The motion along the latter is affected by (i) thermal white noise (diffusion, $D_{i}$ ), (ii) drift in the corresponding structural potential, $V_{i}(x)$, and (iii) discrete colored noise with feedback, originated from the forward/backward reaction events $\mathbf{0} \rightleftarrows \mathbf{1}$ with the rate constants $k_{01}(x), k_{10}(x)$, respectively. It is these events that attach the lower indices, $i \in(0 ; 1)$, to $D_{i}$ and $V_{i}(x)$. Then the evolution equations for the corresponding probability densities $p_{i}(x, t)$ read

$$
\begin{aligned}
& \frac{\partial p_{0}(x, t)}{\partial t}=\left[D_{0} \frac{\partial}{\partial x}\left(\frac{\mathrm{d} V_{0}}{\mathrm{~d} x}+\frac{\partial}{\partial x}\right)-k_{01}(x)\right] \times \\
& \times p_{0}(x, t)+k_{10}(x) p_{1}(x, t), \\
& \frac{\partial p_{1}(x, t)}{\partial t}=\left[D_{1} \frac{\partial}{\partial x}\left(\frac{\mathrm{d} V_{1}}{\mathrm{~d} x}+\frac{\partial}{\partial x}\right)-k_{10}(x)\right] \times \\
& \times p_{1}(x, t)+k_{01}(x) p_{0}(x, t) .
\end{aligned}
$$

The derivation of Eqs. (1) was given in detail in [13$15]$, and their adequacy to the problem in question was substantiated in $[16,17]$. In most systems under study, the 'excitation' rate constant can be associated with a kind of 'pumping' (provided by, e.g., exciting light or maintained substrate/ligand concentration, etc.) and therefore assumed non-distributed, that is, scaled simply as $k_{01}=I$, pumping intensity. Then the 'recombination' rate constant $k_{10}(x)$ remains responsible for a possible feedback between the reaction turnovers and the structural subsystem (as a rule, it is relevant to assume $\left.k_{10}(x) \equiv k_{r}(x) \sim e^{-x}[10,13-17]\right)$. If one is interested in the unidirectional process only (e.g., in the rebinding reaction in the $\mathrm{MbCO}$ system, or the recombination of the photoexcited electron back to the primary donor in an RC), then Eqs. (1) are reduced to the 'sinkSmoluchowski' equation for the survival probability density in the seminal Agmon-Hopfield model [10]:

$$
\frac{\partial p_{1}(x, t)}{\partial t}=\left[D_{1} \frac{\partial}{\partial x}\left(\frac{\mathrm{d} V_{1}}{\mathrm{~d} x}+\frac{\partial}{\partial x}\right)-k_{r}(x)\right] p_{1}(x, t)
$$

Equations (1) and (2), together with the relevant highprecision computer methods, represent the theoretical tools exploited. The above-mentioned electron transfer reactions in an isolated $\mathrm{RC}$ are chosen as our underlying biophysical model. Precisely, it is the forward, very fast electron transfer from the primary electron donor $P$ to the secondary electron acceptor $Q_{B}$, initiated by actinic light, with the subsequent recombination of the charge-separated state $P^{+} Q_{B}^{-}$to the initial state $P Q_{B}$ $[11,18-20]$. This reversible reaction can undergo multiple subsequent turnovers. Due to the presence of a stable optical marker - in particular, the bleaching of the absorption band at $865 \mathrm{~nm}$ indicated the donor photoexcitation $[11,12]$, so that the normalized absorbance changes show the populations of reaction states $P Q_{B}$ and $P^{+} Q_{B}^{-}$- the reaction kinetics can be traced to a high accuracy on a wide time scale by the optical spectroscopy methods; for the relevant setup, see, e.g., [21]. Typical experimental curves represent the time course of the initial charge photoseparation under the action of actinic light of certain intensity $I$ and the exposure duration $t_{\exp }$ with subsequent recombination (which can last from seconds to tens of minutes) after switching-off light $[19,20,22,23]$.

\section{Deciphering the 'Footprints' of Slow Structural Changes}

Thus, assuming that we have sufficiently accurate kinetic data on both the excitation and recombination stages under various (pulsed and continuous) types of excita- 
tion, we can try to uncover that information about the conformational regulation, hidden in kinetic traces.

\subsection{What do the memory effects serve for?}

One of the prime distinctive features usually cited for protein reactions is their non-exponential time course, through which the structural motions show up. Longterm extensive studies of the $\mathrm{Mb}+\mathrm{CO} \rightarrow \mathrm{MbCO}$ reaction, combined with modeling within Eq. (2), has allowed H. Frauenfelder et al. [3, 5, 8, 24] to classify various components of the complex reaction kinetics in regard to their role in hindering the rebinding, etc. What, however, has been totally missed in their analyses is the possibility of the indirect coupling of consecutive reaction turnovers (this can be easily seen just from the very structure of Eq. (2), which involves the unidirectional decay $k_{r}(x)$ only). This possibility looks more than natural, bearing in mind that the slow structural changes initiated by a reaction event may have no time to completely relax before the next turnover (driven by 'pumping' $I$ ) begins. Due to the structurefunction feedback reflected in the $x$-dependence of $k_{r}(x)$, this entails a specific nonlinear coupling, which results in typical synergetic effects like the thresholdlike emergence/disappearance of new stationary (but non-equilibrium) working regimes of the protein macromolecule, bistability, hysteresis, etc. The essence of such intramolecular dynamical self-organization concept can be showed within Eqs. (1) due to the presence of not only the sink terms but also the input ones, especially $k_{01}$, or $I$, as a control parameter.

This indicates the lines of a series of our previous works (e.g., [13-15, 18-20, 23] with the redox reactions in the $\mathrm{RC}$ as the main experimental proving ground. Resuming, it is worth to note the following. Combining fine analysis of the kinetic data under different excitation conditions (that is, varying either the duration or the intensity of actinic light, (multi)pulse excitation included) with analytics and computer simulations of these processes within the framework of Eqs. (1), we have shown that, indeed, there exists a bistability window $\left(I_{1}, I_{2}\right)$, in which a transition between the so-called 'dark' regime of the RC with low charge-separation efficiency (at $I<I_{1}$ ) and the 'light' one with much higher charge-separation efficiency (at $I>I_{2}$ ) can take place, while the both can coexist at $I_{1}<I<I_{2}$. The corresponding hysteretic effects (showing the adaptation properties of the $\mathrm{RC}$ ) and memory effects between consecutive RC cycles have been also shown explicitly. On the whole, these findings indicate a new, quite general physical mechanism of conformational control and provide a new insight into some basic biochemical concepts like the induced fit [25], cooperativity [26], and others.

\subsection{Projection onto single-molecule enzymology}

With the advent of single-molecule spectroscopy, it has become possible to explicitly detect the long series of switchings of one and the same biomolecule between its reaction states. As usual, such single-molecule 'trajectories' undergo a statistical processing in order to directly show the intercycle memory hidden in ensemble experiments, etc. $[9,27,28]$. In the two-state $\mathbf{0} \rightleftarrows \mathbf{1}$ case, the prime statistical characteristics are the on-time distributions (OTD) $f_{\text {on }}(t)$ (assuming that reaction state $\mathbf{1}$ is called 'on') and autocorrelation functions (ACFs) $\langle\xi(t) \xi(0)\rangle$ (assuming that $\xi$ is equal to 1 in state $\mathbf{1}$ and to zero otherwise). It is those quantities that were calculated from the classical experiments on cholesteroloxidase reactions [27]. As it should be expected, they turned out to be clearly nonexponential in time, thereby testifying the strong deviations from standard chemical kinetics and the memory effects originated from structural changeability. The subsequent theoretical works (see, e.g., [16, 29, 30]) were devoted to obtaining such dependences mostly within the models with a restricted number (in fact, 2 or 3 ) of conformation substates. Paradoxically, the authors of those works often ignored the nonequilibrium flow conditions of the process, just like in the Agmon-Hopfield model (cf. [10, 16]). In our previous work [31], we noted that it is Eqs. (1) that are most adequate for calculating the single-molecular statistical characteristics, too. For example, while the OTD function is really given by the solution of Eq. (2),

$f_{\text {on }}(t)=\int k_{r}(x) p_{1}(x, t) d x$

the important point is that the initial distribution $p_{1}(x, 0)$ along the structural variable $x$ should correspond to the normalized stationary distribution $p_{0}^{\text {st }}(x)$ obtained from set (1). Similarly, it can be shown that the normalized ACF reads

$$
\begin{aligned}
& C(t)=\frac{\langle\xi(t) \xi(0)\rangle-\langle\xi(t)\rangle^{2}}{\left\langle\xi(t)^{2}\right\rangle-\langle\xi(t)\rangle^{2}}= \\
& =\frac{\int F(x, t) \mathrm{d} x-\left(\int p_{1}^{\mathrm{st}}(x) \mathrm{d} x\right)^{2}}{\int p_{1}^{\mathrm{st}}(x) \mathrm{d} x-\left(\int p_{1}^{s t}(x) \mathrm{d} x\right)^{2}}
\end{aligned}
$$

where $F(x, t)=\int \mathrm{d} x^{\prime} p_{1}\left(x, t \mid x^{\prime}, 0\right) p_{1}^{\text {st }}\left(x^{\prime}\right)$, and $p_{1}\left(x, t \mid x^{\prime}, 0\right)$ is the Green function of Eqs. 
Numerical solutions of Eqs. (1) and (2) show a great variety of possible OTD/ACF shapes dictated exactly by nonequilibrium (bimodal, in particular) stationary distributions $p_{i}^{\text {st }}(x)$, depending on intensity $I$ and relative positions of minima of potentials $V_{i}(x)$, see Figure for an example. Recently, we have supplied these results with those obtained from solutions of the corresponding stochastic equations with the two noises mentioned in Section 2. Figure shows a very good agreement between the analytic and stochastic modeling (more detailed results will be published elsewhere); we note, however, that it needs quite long turnover sequences containing many thousands of stochastic flips, so that it is a good reminder of the requirements to real biochemical samples used in single-molecule experiments.

\subsection{Probing the protein relaxation peculiarities}

As is mentioned above, it is the nonexponential kinetics of protein reactions that triggered all the further studies in the field. For the first time, it was observed for the $\mathrm{CO}$ rebinding to $\mathrm{Mb}[3]$, and then also for the recombination reaction in the $\mathrm{RC}$ [32]. In both cases, it was a fractional power kinetics of the $(1+t / \tau)^{-\alpha}$ type, witnessing an hierarchical multi-tier structure of the protein energy landscape [5, 33]. However, it was observed at low temperatures only, so that its role in the physiological function could be to some extent questioned. We have modified standard experimental protocols, monitoring the recombination reaction $P^{+} Q_{B}^{-} \rightarrow P Q_{B}$ in the $\mathrm{RC}$ at room temperature, but after a continuous preillumination of different durations $t_{\exp }$ [22]. Here, crucial was the high-precision expansion of kinetic curves in a spectrum of relaxation times; for this purpose, a special version of the maximal entropy method was developed.

The effective time-dependent recombination rate constant (or, better, rate coefficient) $K(t)$ can be expressed by integrating Eq. (2) over $x$; this leads to the kinetic equation $\dot{n}(t)=-K(t) n(t)$ for the population $n(t)$ of state 1 (here, $P^{+} Q_{B}^{-}$) observed in the experiment, where

$$
n(t)=\int p_{1}(x, t) \mathrm{d} x, \quad K(t)=\int \mathrm{d} x k_{r}(x) p_{1}(x, t) / n(t)
$$

and, therefore, $n(t)=n(0) \exp \left(-\int_{0}^{t} K\left(t^{\prime}\right) \mathrm{d} t^{\prime}\right)$. Then $n(t) / n(0)$ can be expanded as

$n(t) / n(0)=\int_{0}^{\infty} g(\tau) \exp (-t / \tau) \mathrm{d} \tau$.

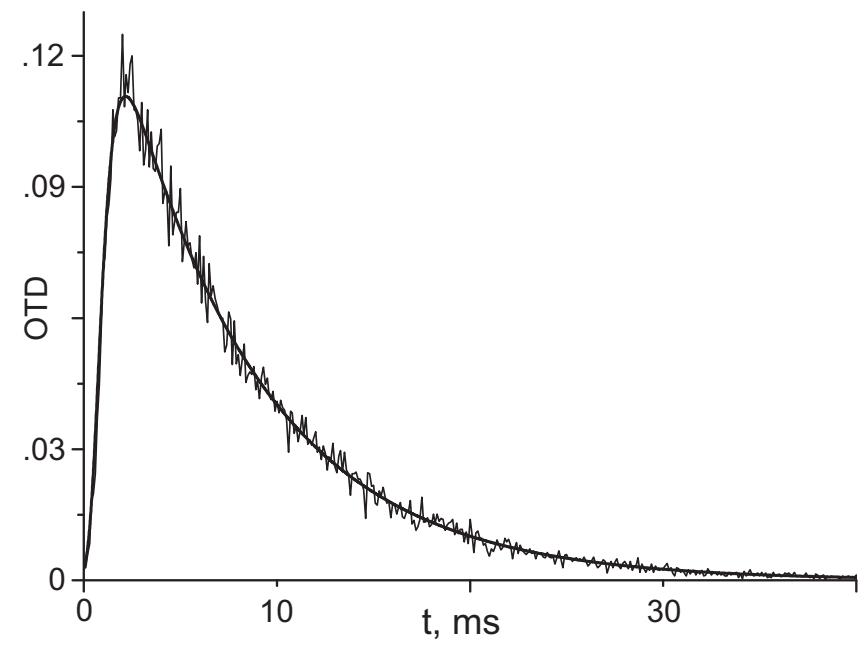

Example of the on-time distribution calculated within Eqs. (1) and (2) (solid line) and from the corresponding stochastic equation. $V_{0}(x)=10(x-7)^{2}, V_{1}(x)=10(x-2)^{2}, I=0.1, k_{r}(x)=e^{-x}$, $D_{0}=D_{1}=0.1$. Conventionally, such a shape of the OTD is associated with the presence of the third (intermediate) reaction state. Here, we see that it can be observed even in the two-state model due to the consistent account for the conformational motion

It turns out that, under the pre-illumination during $t_{\exp }$ of about tens of seconds, the recombination kinetics strongly differs from that of a fast $(\sim 1 \mathrm{~s})$ one-exponential decay usually detected after the pulsed photoexcitation. Precisely, its spectrum $g(\tau)$ consists of several (3 to 5 ) well-separated peaks, with the positions of their maxima growing linearly with $t_{\text {exp }}$. This is practically equivalent to the hyperbolic decrease of $K(t)$ of each component in time, $K(t)=1 /\left(\tau_{0}+v t\right)$, and integrating the kinetic equation immediately yields:

$n(t)=n(0) /\left(1+v t / \tau_{0}\right)^{-1 / v}$

(the component indices are omitted here). The fractional power law (7) implies the known $\gamma$-distribution for relaxation times, which perfectly describes, indeed, the spectra $g(\tau)$ obtained from the experiment. In addition, the kinetics time course restored from these distributions turns out to be almost identical to the experimental one. Thus, we have practically observed the manifestations of the so-called taxonomic states of the energy landscape $[5,33]$ at room temperature, with the $\gamma$-distribution reflecting some generality of the character of the relaxation between substates within the taxonomic states. This indicates the functional significance of the hierarchical protein relaxation and a possibility of the selective control over them by actinic light, in particular (cf. [5]). 


\section{Concluding Remarks}

All the expounded above shows a somewhat unexpected aptitude and generality of the described tools at the analyses of rather different and complex aspects of the structure-function coupling in proteins. Of course, within the framework of equations like Eqs. (1) and (2), it is hard to go deeper into specific structural details, important for a given reaction - there are many other powerful methods aimed at this daunting task. At the same time, as noted in [16], under current circumstances, the approach presented here is "of the right level of complexity, thus easily accessible computationally while producing meaningful physical insight".

This work is performed in part within the project 'Fundamental properties of physical systems' (the NAS of Ukraine).

1. M. Karplus, J. Phys. Chem. B 104, 11 (2000).

2. C. Anfinsen, Science 181, 223 (1973).

3. R.H. Austin, K. Beeson, L. Eisenstein, H. Frauenfelder, I.C. Gunsalus, and V.P. Marshall, Phys. Rev. Lett. 32, 403 (1974).

4. G. Weber, Adv. Prot. Chem. 29, 1 (1975).

5. H. Frauenfelder, G. Chen, J. Berendzen, P.W. Fenimore, H. Jansson, B.H. McMahon, I.R. Stroe, J. Swenson, and R.D. Young, PNAS USA 106, 5129 (2009).

6. R. Laughlin and D. Pines, PNAS USA 97, 28 (2000).

7. C. Jelsch, M.M. Teeter, V. Lamzin, V. Pichon-Pesme, R.H. Messing, and C. Lecomte, PNAS USA 97, 3171 (2000).

8. R.D. Young and P.W. Fenimore, Biochim. Biophys. Acta 1814, 916 (2011).

9. A.A. Deniz, S. Mukhopadhyay, and E. Lemke, J. R. Soc. Interface 5, 15 (2008).

10. N. Agmon and J.J. Hopfield, J. Chem. Phys. 78, 6947 (1983).

11. M.Y. Okamura and G. Feher, Ann. Rev. Biochem. 61, 861 (1992).

12. M.R. Gunner, Curr. Topics Bioenerg. 16, 319 (1991).

13. L.N. Christophorov, Phys. Lett. A 205, 14 (1995).

14. L.N. Christophorov, Dopov. Nats. Akad. Nauk Ukr. 12, 96 (1998).

15. L.N. Christophorov, A.R. Holzwarth, V.N. Kharkyanen, and F. van Mourik, Chem. Phys. 256, 45 (2000).
16. N. Agmon, J. Phys. Chem. B 104, 7830 (2000).

17. L.N. Christophorov and V.N. Kharkyanen, Chem. Phys. Res. J. 1, 1 (2007).

18. G.A. Abgaryan, L.N. Christophorov, A.O. Goushcha, A.R. Holzwarth, V.N. Kharkyanen, P.P. Knox, and E.P. Lukashev, J. Biol. Phys. 24, 1 (1998).

19. Yu.M. Barabash, N.M. Berezetskaya, L.N. Christophorov, A.O. Goushcha, and V.N. Kharkyanen, J. Chem. Phys. 116, 4339 (2002).

20. A.O. Goushcha, A.J. Manzo, G.W. Scott, L.N. Christophorov, P.P. Knox, Yu.M. Barabash, M.T. Kapoustina, N.M. Berezetska, and V.N. Kharkyanen, Biophys. J. 84, 1146 (2003).

21. E.P. Lukashev, P.P. Knox, A.B. Rubin, M.V. Olenchuk, Yu.M. Barabash, N.M. Berezetskaya, and V.N. Kharkyanen, Biofiz. 54, 296 (2009).

22. V.N. Kharkyanen, Yu.M. Barabash, N.M. Berezetskaya, E.P. Lukashev, P.P. Knox, and L.N. Christophorov, Chem. Phys. Lett. 512, 113 (2011).

23. L.N. Christophorov, Int. J. Quant. Chem. 110, 62 (2010).

24. H. Frauenfelder, P.G. Wolynes, and R.H. Austin, Rev. Mod. Phys. 71, S419 (1999).

25. D.E. Koshland, jr., PNAS USA 44, 98 (1958).

26. J. Ricard and A. Cornish-Bowden, Eur. J. Biochem. 166, 255 (1987)

27. X.S. Xie and H.P. Lu, J. Biol. Chem. 274, 15967 (1999).

28. H.P. Lu, L. Xun, and X.S. Xie, Science 282, 1877 (1998).

29. G.K. Schenter, H.P. Lu, and X.S. Xie, J. Phys. Chem. A 103, 10477 (1999).

30. S. Young and J. Cao, J. Chem. Phys. 117, 10996 (2002).

31. L.N. Christophorov, A.R. Holzwarth, and V.N. Kharkyanen, Ukr. J. Phys. 48, 672 (2003).

32. D. Kleinfeld, M.Y. Okamura, and G. Feher, Biochemistry 23, 5780 (1984).

33. Yu.F. Krupyanskii and V.I. Gol'danskii, Physics-Uspekhi 45, 1131 (2002).

Received 06.10.11

НЕПРЯМІ СВІДОЦТВА КОНФОРМАЦІЙНОЇ РЕГУЛЯЦІЇ У РЕАКЦІЯХ БІЛКІВ: ЯК БАГАТО МОЖНА ДІЗНАТИСЯ?

Л.М. Христофоров

$\mathrm{P}$ е $з$ ю м е

Майже всі реакції білків демонструють відхилення від простої поведінки в межах стандартної (біо)хімічної кінетики. Це 
зумовлено виключною структурною лабільністю білкових макромолекул, зазвичай не менш важливою для ефективності реакції, ніж властивості активного центру. Розкриття механізмів структурної регуляції наштовхується на значні труднощі з огляду на їхній прихований характер, оскільки сучасні експериментальні та обчислювальні засоби ще далеко не доста- тні для одночасного моніторинга перебігу реакції та супутніх конформаційних змін, сліди яких доводиться розшифровувати тільки з кінетики реакціі. Тим не менш, можливо дійти до надійних висновків щодо функціонування білків та характеру їхньої структурної релаксації за допомогою зручного та обчислювально доступного підходу, що викладається в даній роботі. 